\title{
Rapid identification of microbial contaminants in pharmaceutical products using a PCA/ LDA-based FTIR-ATR method
}

\author{
Natália Monte Rubio de Brito, Felipe Rebello Lourenço ${ }^{(-*}$ \\ Departamento de Farmácia, Faculdade de Ciências Farmacêuticas, Universidade de São Paulo \\ São Paulo, São Paulo, Brazil
}

\begin{abstract}
Microbiological quality of pharmaceuticals is fundamental in ensuring efficacy and safety of medicines. Conventional methods for microbial identification in non-sterile drugs are widely used; however they can be time-consuming and laborious. The aim of this paper was to develop a chemometricbased rapid microbiological method (RMM) for identifying contaminants in pharmaceutical products using Fourier transform infrared with attenuated total reflectance spectrometry (FTIRATR). Principal components analysis (PCA) and linear discriminant analysis (LDA) were used to obtain a predictive model capable of distinguishing Bacillus subtilis (ATCC 6633), Candida albicans (ATCC 10231), Enterococcus faecium (ATCC 8459), Escherichia coli (ATCC 8739), Micrococcus luteus (ATCC 10240), Pseudomonas aeruginosa (ATCC 9027), Salmonella typhimurium (ATCC 14028), Staphylococcus aureus (ATCC 6538), and Staphylococcus epidermidis (ATCC 12228) microbial growth. FTIR-ATR spectra provide data on proteins, DNA/RNA, lipids, and carbohydrates constitution of microbial growth. Microbial identification provided by PCA/LDA based on FTIRATR method were compatible with those obtained using traditional microbiological methods. The chemometric-based FTIR-ATR method for rapid identification of microbial contaminants in pharmaceutical products was validated by assessing the sensitivity ( $93.5 \%)$, specificity $(83.3 \%)$, and limit of detection (17-23 CFU/mL of sample). Therefore, we propose that FTIR-ATR spectroscopy may be used for rapid identification of microbial contaminants in pharmaceutical products and taking into account the samples studied.
\end{abstract}

Keywords: Infrared spectrometry (IR). Principal components analysis (PCA). Linear discriminant analysis (LDA). Rapid microbiological methods (RMM). Microbial identification. Chemometric tools.

\section{INTRODUCTION}

The microbiological quality of non-sterile products covers two relevant aspects: First the assessment of microbial burden (microbial count) (United States Pharmacopeia, 2016a; ANVISA, 2010) and secondly the absence of pathogenic microorganisms (United States Pharmacopeia, 2016b; ANVISA, 2010). The absence of pathogenic microorganisms is required by health authorities depending on their route of administration. Pharmaceutical products for oral use requires the

*Correspondence: F. R. Lourenço. Departamento de Farmácia. Faculdade de Ciências Farmacêuticas. Universidade de São Paulo. Av. Prof. Lineu Prestes, 580 - Bloco 13. CEP 05508-000 - São Paulo - SP - Brazil. E-mail: feliperl@usp.br absence of microorganisms of the genus Salmonella and coliform bacteria, such as Escherichia coli. On the other hand, topical products require the absence of Staphylococcus aureus and Pseudomonas aeruginosa (United States Pharmacopeia, 2016b; ANVISA, 2010).

Microbialidentification methods usually employed for pharmaceutical products are those described in the official compendia, such as the Brazilian pharmacopeia (ANVISA, 2010), and United States pharmacopeia (United States Pharmacopeia, 2016b; ANVISA, 2010). These are traditional methods that involve two steps: 1) enrichment of microbial culture in non-selective media; and 2) identification using culture media for selective growth and/or biochemical tests. Usually, these methods are laborious since they involve several selective culture media, and can take 
up to several weeks to provide microbial identification (Denyer, Baird, 2007).

Rapid Microbiological Methods (RMM) have been developed as alternatives to traditional microbiological methods for quantitative and qualitative analysis of foods, cosmetics, medicines, and clinical samples (Ester, 2003; Pinto et al., 2015). Despite the advantages of rapid microbiological methods (RMM), there are still some barriers, mainly due to regulatory issues. Method validation is critical step for the approval of RMM by regulatory agencies. Additionally, the equivalence of the RMM with the traditional method should be demonstrated through comparative experiments (United States Pharmacopeia, 2016c).

The RMM are generally chosen considering the purpose of the test and the compatibility with the product. The main methods are: 1) methods based on microbial growth, such as electrochemical methods, bioluminescence methods, methods based on detection of gas production, and employment of chromogenic substrates (Bugno et al., 2015; Ferreira et al., 2014; Parveen et al., 2011; Shah, Naseby, 2015; Verdonk et al., 2010; Lourenço et al., 2015; Bugno et al., 2018); 2) methods based on viability, such as flow cytometry and ATP detection (Taguri et al., 2011; Ugavora et al., 2016); 3) methods based on phenotypic analysis, such as immuno-fluorescence techniques, infrared spectrometry (FTIR), mass spectroscopy (MALDI-TOF), and analysis of fatty acids profile by gas chromatography (GC) (David, Maurer; 2010; Filip et al., 2014; Fischer et al., 2006; Helm, Naumann 1995; Kuligowski et al., 2012; Liu et al., 2016; Pacheco, Pinto, 2010; Song et al., 2016; Tidwell et al., 2015; Tong et al., 2010; Wu et al., 2013); and 4) methods based on genotypic analysis, such as PCR techniques and fingerprint identification (Kane et al., 2009; Maurischat et al., 2015).

Considering the limitations of traditional methods, such as being laborious and time-consuming, the development of RMM for the identification of contaminants in pharmaceutical products is of interest for the pharmaceutical industry. The Fourier transform infrared with attenuated total reflectance spectrometry (FTIR-ATR) has advantages, such as a reduced number of steps involved in microbial identification, quick results, automation, and tracking data (David, Maurer, 2010; Filip et al., 2014; Fischer et al., 2006; Helm, Naumann, 2006; Kuligowski et al. 2012; Tidwell et al., 2015).

The FTIR/ATR spectra allow us to determine the biochemical qualitative composition of microbial cells, including the composition of proteins, lipids, carbohydrates, and DNA/RNA. Chemometric tools such as Principal Component Analysis (PCA) and Linear Discriminant Analysis (LDA) are useful to establish classification models based in FTIR/ATR spectra information. PCA is a multivariate statistical tool that allows for reducing the number of original variables by obtaining new variables (principal components) with minimal information lost due to data correlation (Paiva, 2006; Hongyu et al., 2015). LDA is a multivariate statistical tool used for classification purposes based on the difference of among the groups regarding several predictive variables (Varella, 2010).

The main advantage of multivariate chemometric tools is the reduction of the number of variables to be considered due to the low variability or redundancy due to the data correlation. On the other hand, chemometricbased methods require dedicated analysis software due to the complex calculations involved (Hongyu et al., 2015; Varella, 2010).

Therefore, this work aims to develop and validate an FTIR-ATR for rapid identification of contaminants in pharmaceutical products. Chemometric tools such as PCA and LDA were used to establish a model capable of classifying the contaminants in pharmaceutical products with assertiveness. Thus, FTIR-ATR may complement (or even replace) the conventional microbiological methods used in Chapter $<62>$ "Microbial examination of nonsterile products: tests for specified microorganisms" of USP (United States Pharmacopeia, 2016b).

\section{MATERIAL AND METHODS}

\section{Pharmaceutical product sample preparation and pre-incubation}

Pharmaceutical products (A: acetaminophen oral solution, B: dipyrone oral solution, $\mathrm{C}$ : chlorhexidine digluconate topical solution) were intentionally contaminated with $10^{2}-10^{3} \mathrm{CFU}$ (Colony Forming Units) of Bacillus subtilis (ATCC 6633) (A: $\mathrm{n}=5 ; \mathrm{B}: \mathrm{n}=5$; and $\mathrm{C}: \mathrm{n}=5)$, Candida albicans (ATCC 10231) (A: $\mathrm{n}=5$; B: $\mathrm{n}=5$; and $\mathrm{C}: \mathrm{n}=5$ ), Enterococcus faecium (ATCC 8459) $(\mathrm{A}: \mathrm{n}=5 ; \mathrm{B}: \mathrm{n}=5$; and $\mathrm{C}: \mathrm{n}=5)$, Escherichia coli (ATCC 8739) (A: $\mathrm{n}=5 ; \mathrm{B}: \mathrm{n}=5$; and $\mathrm{C}: \mathrm{n}=5)$, Micrococcus luteus (ATCC 10240) (A: $\mathrm{n}=5 ; \mathrm{B}: \mathrm{n}=5$; and $\mathrm{C}: \mathrm{n}=5)$, Pseudomonas aeruginosa (ATCC 9027) (A: $\mathrm{n}=5 ; \mathrm{B}: \mathrm{n}=$ 5; and C: $\mathrm{n}=5$ ), Salmonella typhimurium (ATCC 14028) $(\mathrm{A}: \mathrm{n}=5 ; \mathrm{B}: \mathrm{n}=5$; and C: $\mathrm{n}=5)$, Staphylococcus aureus 
(ATCC 6538) (A: $\mathrm{n}=5 ; \mathrm{B}: \mathrm{n}=5$; and $\mathrm{C}: \mathrm{n}=5)$, and Staphylococcus epidermidis (ATCC 12228) (A: $\mathrm{n}=5$; B: $\mathrm{n}=5$; and $\mathrm{C}: \mathrm{n}=5$ ). All microbial strains were supplied by the Instituto Adolfo Lutz (IAL, Brazil).

Aliquots of $10 \mathrm{~mL}$ of the pharmaceutical products were transferred to $90 \mathrm{~mL}$ of sterile $0.9 \%$ sodium chloride (INLAB, Brazil) solution, stirred, and filtered through a sterile $0.45 \mu \mathrm{m}$ cellulose ester membrane (Millipore, USA). The membranes were aseptically transferred to test tubes containing $10 \mathrm{~mL}$ of tryptic soy broth (DIFCO, USA, pancreatic digest of casein $17.0 \mathrm{~g} / \mathrm{L}$, papaic digest of soybean $3.0 \mathrm{~g} / \mathrm{L}$, dextrose $2.5 \mathrm{~g} / \mathrm{L}$, sodium chloride $5.0 \mathrm{~g} / \mathrm{L}$, and dipotassium phosphate $2.5 \mathrm{~g} / \mathrm{L}$ ). Test tubes were incubated in a bacteriological oven for 18-24 h at $37 \pm 1{ }^{\circ} \mathrm{C}$. Microbial suspension growth obtained after incubation was analyzed using conventional microbiological tests for specified microorganisms, as described in Chapter $<62>$ "Microbial examination of nonsterile products: tests for specified microorganisms" of the USP (United States Pharmacopeia, 2016b), and by FTIR-ATR.

\section{Microbiological tests for specified microorganisms}

All microbial tests for specified microorganisms were performed according to Chapter $<62>$ "Microbial examination of nonsterile products: tests for specified microorganisms" of the USP (United States Pharmacopeia, 2016b).

Aliquots of microbiological growths were transferred to selective culture media using a $10 \mu \mathrm{L}$ sterile loop. MacConkey Agar (DIFCO, USA, pancreatic digest of gelatin $17.0 \mathrm{~g} / \mathrm{L}$, meat and casein peptones 3.0 $\mathrm{g} / \mathrm{L}$, lactose monohydrate $10.0 \mathrm{~g} / \mathrm{L}$, sodium chloride 5.0 $\mathrm{g} / \mathrm{L}$, bile salts $1.5 \mathrm{~g} / \mathrm{L}$, agar $13.5 \mathrm{~g} / \mathrm{L}$, neutral red 30.0 $\mathrm{mg} / \mathrm{L}$ crystal violet $1 \mathrm{mg} / \mathrm{L}$ ), Cetrimide Agar (DIFCO, USA, pancreatic digest of gelatin $20 \mathrm{~g} / \mathrm{L}$, magnesium chloride $1.4 \mathrm{~g} / \mathrm{L}$, dipotassium sulfate $10.0 \mathrm{~g} / \mathrm{L}$, cetrimide $0.3 \mathrm{~g} / \mathrm{L}$, agar $13.6 \mathrm{~g} / \mathrm{L}$, glycerol $10.0 \mathrm{~mL} / \mathrm{L}$ ), and Mannitol Salt Agar (BD, USA, pancreatic digest of casein $5.0 \mathrm{~g} / \mathrm{L}$, peptic digest of animal tissue $5.0 \mathrm{~g} / \mathrm{L}$, beef extract 1.0 $\mathrm{g} / \mathrm{L}$, D-mannitol $10.0 \mathrm{~g} / \mathrm{L}$, sodium chloride $75.0 \mathrm{~g} / \mathrm{L}$, agar $15.0 \mathrm{~g} / \mathrm{L}$, phenol red $25 \mathrm{mg} / \mathrm{L}$ ) were employed to identify Escherichia coli, Pseudomonas aeruginosa, and Staphylococcus aureus, respectively. Test samples intentionally contaminated with $<100 \mathrm{CFU} / \mathrm{mL}$ of each test-microorganisms were subject to membrane filtration. Membranes were rinsed with three portions of $100 \mathrm{~mL}$ of sterile $0.9 \%$ sodium chloride solution, in order to remove sample residue.

The expected cultural responses of Bacillus subtilis (ATCC 6633), Candida albicans (ATCC 10231), Enterococcus faecium (ATCC 8459), Escherichia coli (ATCC 8739), Micrococcus luteus (ATCC 10240), Pseudomonas aeruginosa (ATCC 9027), Salmonella typhimurium (ATCC 14028), Staphylococcus aureus (ATCC 6538), and Staphylococcus epidermidis (ATCC 12228) microbial growth in MacConkey Agar, Cetrimide Agar, and Mannitol Salt Agar were presented in Table I.

\section{Fourier Transform Infrared with Attenuated Total Reflectance Spectroscopy (FTIR-ATR)}

Microbial growth suspensions obtained from pharmaceutical products using tryptic soy broth were centrifuged at $1,500 \mathrm{rpm}$ for $60 \mathrm{~min}$. Supernatant culture media were disposed, and the bio-masses were used for FTIR-ATR measurements. Spectra of biomasses were obtained using a Fourier transform infrared spectrophotometer (Shimadzu, IRAffinity-1, Kyoto, Japan) equipped with an attenuated total reflectance apparatus. Spectra were collected in transmittance mode between 4,000 and $550 \mathrm{~cm}^{-1}$. Each spectrum was obtained from 32 scans, and the mean values were used during data analysis.

\section{Data analysis}

Principal component analysis (PCA), linear discriminant analysis (LDA), cross validation and external validation were carried out using Minitab $^{\mathrm{TM}} 17$ software. First order derivative and smoothed spectra in the wavelength between 2,000 and $800 \mathrm{~cm}^{-1}$ were used to calculate PCA and LDA. Prediction models were constructed using 180 spectra of Bacillus subtilis (ATCC 6633, $\mathrm{n}=20$ ), Candida albicans (ATCC 10231, $\mathrm{n}=20$ ), Enterococcus faecium (ATCC 8459, $\mathrm{n}=20$ ), Escherichia coli (ATCC 8739, $\mathrm{n}=20$ ), Micrococcus luteus (ATCC 10240, $\mathrm{n}=20$ ), Pseudomonas aeruginosa (ATCC 9027, $\mathrm{n}=20$ ), Salmonella typhimurium (ATCC $14028, \mathrm{n}=20$ ), Staphylococcus aureus (ATCC 6538, n $=20$ ), and Staphylococcus epidermidis (ATCC 12228, $\mathrm{n}=20$ ) based on PCA and LDA results. A predictive model was constructed using the spectra obtained from microbial growth in TSB culture medium without test samples. In addition, external validation of the predictive model was performed using microbial growth 
TABLE I - Expected cultural responses of Bacillus subtilis (ATCC 6633), Candida albicans (ATCC 10231), Enterococcus faecium (ATCC 8459), Escherichia coli (ATCC 8739), Micrococcus luteus (ATCC 10240), Pseudomonas aeruginosa (ATCC 9027), Salmonella typhimurium (ATCC 14028), Staphylococcus aureus (ATCC 6538), and Staphylococcus epidermidis (ATCC 12228) microbial growth in MacConkey Agar, Cetrimide Agar, and Mannitol Salt Agar

\begin{tabular}{lccc}
\hline Microorganism & MacConkey Agar & Cetrimide Agar & Mannitol Salt Agar \\
\hline B. subtilis & Poor growth & Poor growth & Poor growth \\
\hline C. albicans & Poor growth & Poor growth & Poor growth \\
\hline E. faecium & Poor growth & Poor growth & Poor growth \\
\hline
\end{tabular}

E. coli Good growth, pink to red colonies, with bile precipitate
Growth inhibited Growth inhibited

\begin{tabular}{lccc}
\hline M. luteus & Poor growth & Poor growth & Poor growth \\
\hline P. aeruginosa & Poor growth & $\begin{array}{l}\text { Good growth, yellow- } \\
\text { green to blue colonies }\end{array}$ & Poor growth \\
\hline S. typhimurium & Good growth, colorless colonies & Poor growth & Poor growth \\
\hline S. aureus & Poor growth & Growth inhibited & Good growth, yellow colonies \\
\hline S. epidermidis & Poor growth & Poor growth & Good growth, red colonies \\
\hline
\end{tabular}

in TSB culture medium in the presence of test samples. A total of 108 spectra of Bacillus subtilis (ATCC 6633, $\mathrm{n}=10$ ), Candida albicans (ATCC 10231, $\mathrm{n}=10$ ), Enterococcus faecium (ATCC 8459, $\mathrm{n}=14$ ), Escherichia coli (ATCC 8739, $\mathrm{n}=15$ ), Micrococcus luteus (ATCC 10240, $\mathrm{n}=13$ ), Pseudomonas aeruginosa (ATCC 9027, $\mathrm{n}=13$ ), Salmonella typhimurium (ATCC 14028, $\mathrm{n}=$ 5), Staphylococcus aureus (ATCC 6538, $\mathrm{n}=14$ ), and Staphylococcus epidermidis (ATCC 12228, $\mathrm{n}=14$ ) were used for external validation.

\section{Validation of FTIR-ATR method for rapid identification}

The validation of qualitative methods is often performed by assessing the sensitivity, specificity and limit of detection, as described in the literature (Trullols et al., 2004; Lourenço et al., 2005; United States Pharmacopeia, 2016c).
The FTIR-ATR method for rapid identification of microbial contaminants in pharmaceutical products was adopted as a classification test (qualitative), which may indicate positive (or negative) identification of a specified microorganism. Thus, the FTIR-ATR method was validated by assessing the sensitivity and specificity. Sensitivity was determined as the ratio of the number positive results obtained using the FTIRATR method and the number of products that exhibit microbial growth. In other words, sensitivity indicates the true positive rate. On the other hand, specificity was determined as the ratio of samples not intentionally contaminated and the number of samples that did not present microbial growth. In other words, specificity indicates the true negative rate. Test samples subject to sensitivity and specificity tests were intentionally contaminated with less than $100 \mathrm{CFU} / \mathrm{mL}$ of each test-microorganism. 
In addition, the FTIR-ATR method was validated by assessing the limit of detection. Microbial growth of each microorganism was obtained after overnight incubation at $37 \pm 1{ }^{\circ} \mathrm{C}$. Ten-fold serial dilutions were prepared using tryptic soy broth. Aliquots of each dilution were transferred to Petri dishes, and 15$20 \mathrm{~mL}$ of melted tryptic soy agar (Difco, USA) was transferred. Test tubes and Petri dishes were incubated in the bacteriological oven for $18-24 \mathrm{~h}$ at $37 \pm 1{ }^{\circ} \mathrm{C}$. Test tubes were inspected for presence/absence of microbial growth. The numbers of CFU were manually counted from Petri dishes. The limit of detection was determined as the number of CFU obtained from the last ten-fold dilution tube that showed presence of microbial growth. Microbial growth in TSB culture medium obtained during limit of detection test were subject to FTIR analysis.

\section{RESULTS AND DISCUSSION}

\section{FTIR-ATR of microbial growth}

Figure 1 shows the mean FTIR-ATR spectrabetween 800 and $2000 \mathrm{~cm}^{-1}$ after first derivative and smoothing of Bacillus subtilis (ATCC 6633), Candida albicans (ATCC 10231), Enterococcus faecium (ATCC 8459), Escherichia coli (ATCC 8739), Micrococcus luteus (ATCC 10240), Pseudomonas aeruginosa (ATCC 9027), Salmonella typhimurium (ATCC 14028), Staphylococcus aureus (ATCC 6538), and Staphylococcus epidermidis (ATCC 12228) microbial growth.

FTIR-ATR spectra provide data on protein, DNA/ RNA, lipids, and carbohydrate constitution of the microbial growth. Intense and broad amide bands around $1,660 \mathrm{~cm}^{-1}$ and $1,540 \mathrm{~cm}^{-1}$ were obtained due to the main spectral contribution from proteins. In addition, less intense strongly overlapped bands from proteins, DNA/ RNA, lipids and carbohydrates appear between 1,500 $\mathrm{cm}^{-1}$ and $950 \mathrm{~cm}^{-1}$. It was noted that the differences in the constitution of the cellular wall influenced the resulting spectra. These differences may be explained due to the presence of higher amounts of peptidoglycan in Grampositive bacteria and the presence of lypopolysaccharides (LPS) in Gram-negative bacteria (David, Maurer, 2010; Helm, Naumann, 1995).

A very high similarity and no significant band shifts were observed from FTIR-ATR spectra obtained from all microbial growths. However, slight changes in the absorbance ratios could be identified due to qualitative/ quantitative differences of protein, DNA/RNA, lipids, and carbohydrate constitution of microbial growth (Kuligowski et al., 2012).

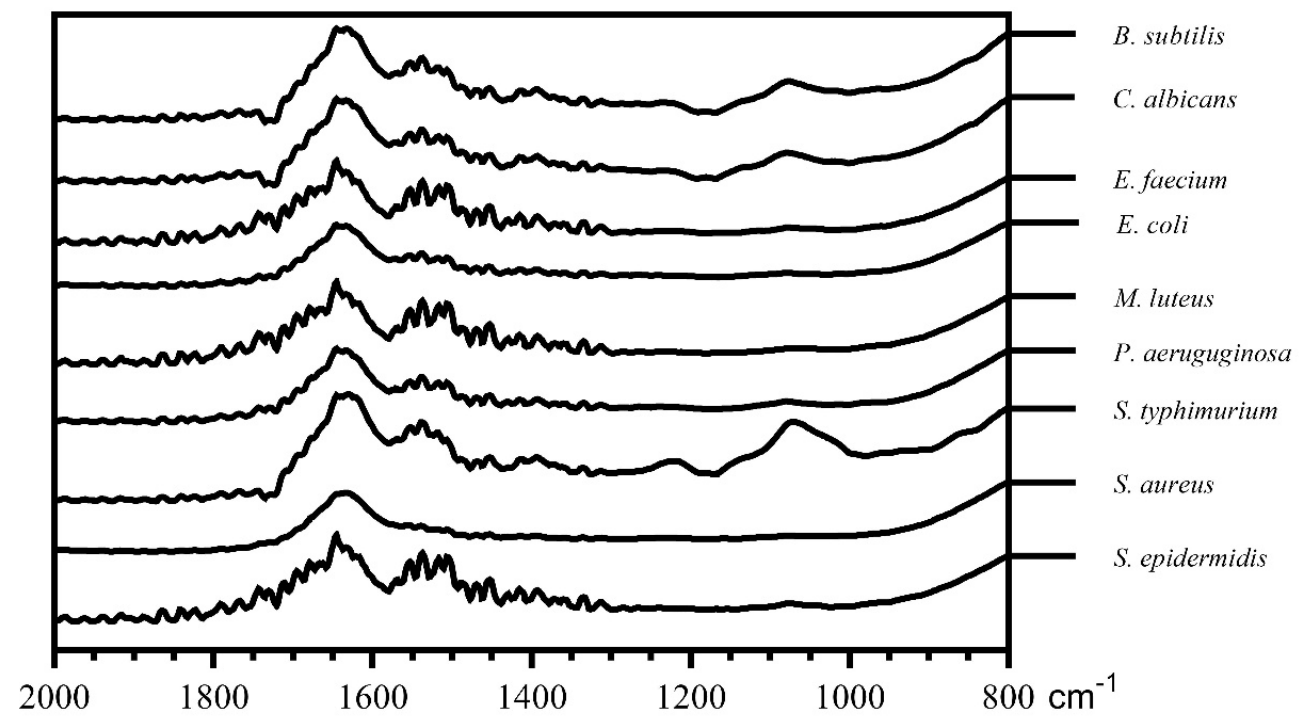

FIGURE 1 - FTIR-ATR spectra between 800 and $2000 \mathrm{~cm}^{-1}$ after first derivative and smoothing of Bacillus subtilis (ATCC 6633), Candida albicans (ATCC 10231), Enterococcus faecium (ATCC 8459), Escherichia coli (ATCC 8739), Micrococcus luteus (ATCC 10240), Pseudomonas aeruginosa (ATCC 9027), Salmonella typhimurium (ATCC 14028), Staphylococcus aureus (ATCC 6538), and Staphylococcus epidermidis (ATCC 12228) microbial growth. 
Data exploration using Principal

Component Analysis (PCA)

A PCA model was constructed using a calibration set with 120 spectra, as described in the section Data analysis. A summary of PCA results is shown in Table II. A PCA model using 4 PCs explains together $98.2 \%$ of the variance and provides a good class separation among Bacillus subtilis (ATCC 6633), Candida albicans (ATCC 10231), Enterococcus faecium (ATCC 8459), Escherichia coli (ATCC 8739), Micrococcus luteus (ATCC 10240), Pseudomonas aeruginosa (ATCC 9027), Salmonella typhimurium (ATCC 14028), Staphylococcus aureus (ATCC 6538), and Staphylococcus epidermidis (ATCC 12228). Score plots of PC1 vs. PC2 vs. PC3 obtained from Principal Component Analysis are shown in Figure 2. Despite the good class separation obtained, PCA is often used to explore data sets as an unsupervised classification method, as well as to detect outliers. Thus, a linear discriminant analysis (LDA) was performed in order to construct a classification model with satisfactory predictive ability.

\section{Data classification using Linear Discriminant Analysis (LDA)}

Classification models were obtained using linear discriminant analysis (LDA) with 4 PC predictors. An LDA model with 4 PC predictors provided good class separation with a reasonable number of PCs, which was confirmed by high values of correct predictions obtained from cross-validation. Thus, this predictor model was adopted for rapid identification of microbial contaminants in pharmaceutical products. A summary of the confusion matrix obtained with this prediction model is shown in Table III.

An external validation was performed for challenging the prediction model. Microbial growth obtained from pharmaceutical products intentionally contaminated with all microorganisms (see section Data analysis) was used for external validation. LDA model with 4 PCs predictors provided correct predictions for 94\% (101 in 108) microbial growths obtained from pharmaceutical products.

Despite the very high similarity and no significant band shifts observed from FTIR-ATR spectra (Figure
1), PCA (Figure 2) and LDA (Table III) models were able to correctly classify the results obtained from microbial growth of different microorganisms. None of the three different pharmaceutical products studied showed interference and we found no statistical significance among the results obtained from these products.

All classifications performed using PCA/LDA based on the FTIR-ATR method were in accordance with those microbiological identifications obtained from traditional microbiological methods using MacConkey Agar, Cetrimide Agar, and Mannitol Salt Agar. Moreover, the FTIR-ATR method provided much faster microbial identification comparing to traditional methods. Microbial identification using the FTIRATR method may be obtained in a few minutes, while traditional microbiological methods may range from days to weeks.

The FTIR-ATR method for rapid identification of microbial contaminants in pharmaceutical products was validated by assessing the sensitivity and specificity. A summary of the results from sensitivity and specificity was presented in Table IV. The sensitivity was found to be $93.5 \%$, which indicates good capability of the FTIRATR method to detect the presence of microorganisms. In other words, the FTIR-ATR method was able to correctly identify a specified microorganism in 935 from 1,000 tests. Moreover, specificity was found to be $83.3 \%$, which indicates that in 833 of 1,000 tests, we found a true negative result.

The absence of pathogenic microorganisms in nonsterile pharmaceutical products is a quality requirement (ANVISA, 2010; United States Pharmacopeia, 2016c). Pharmaceutical products for oral use require an absence of Salmonella and Escherichia coli, while topical products require the absence of Staphylococcus aureus and Pseudomonas aeruginosa. Nevertheless Salmonella and Escherichia coli were included in the validation in order to assess whether the FTIR-ATR method can distinguish among pathogenic and non-pathogenic microorganisms.

In addition, the FTIR-ATR method was validated by assessing the limit of detection. The limit of detection was determined as the number of CFUs obtained from the last ten-fold dilution tube that showed presence of microbial growth, and it was found to be between 17 and $23 \mathrm{CFU} / \mathrm{mL}$ of sample for all tested microorganisms. 
TABLE II - Principal components analysis (PCA) results obtained from FTIR-ATR spectra between 800 and $2000 \mathrm{~cm}^{-1}$ after first derivative and smoothing of Bacillus subtilis (ATCC 6633), Candida albicans (ATCC 10231), Enterococcus faecium (ATCC 8459), Escherichia coli (ATCC 8739), Micrococcus luteus (ATCC 10240), Pseudomonas aeruginosa (ATCC 9027), Salmonella typhimurium (ATCC 14028), Staphylococcus aureus (ATCC 6538), and Staphylococcus epidermidis (ATCC 12228) microbial growth

\begin{tabular}{cccc}
\hline $\mathbf{P C}$ & Eigenvalues & Individual Contribution & Accumulative contribution \\
\hline $\mathbf{1}$ & 379.11 & $60.9 \%$ & $60.9 \%$ \\
\hline $\mathbf{2}$ & 145.63 & $23.4 \%$ & $84.4 \%$ \\
\hline $\mathbf{3}$ & 66.80 & $10.7 \%$ & $95.1 \%$ \\
\hline $\mathbf{4}$ & 19.34 & $3.1 \%$ & $98.2 \%$ \\
\hline
\end{tabular}

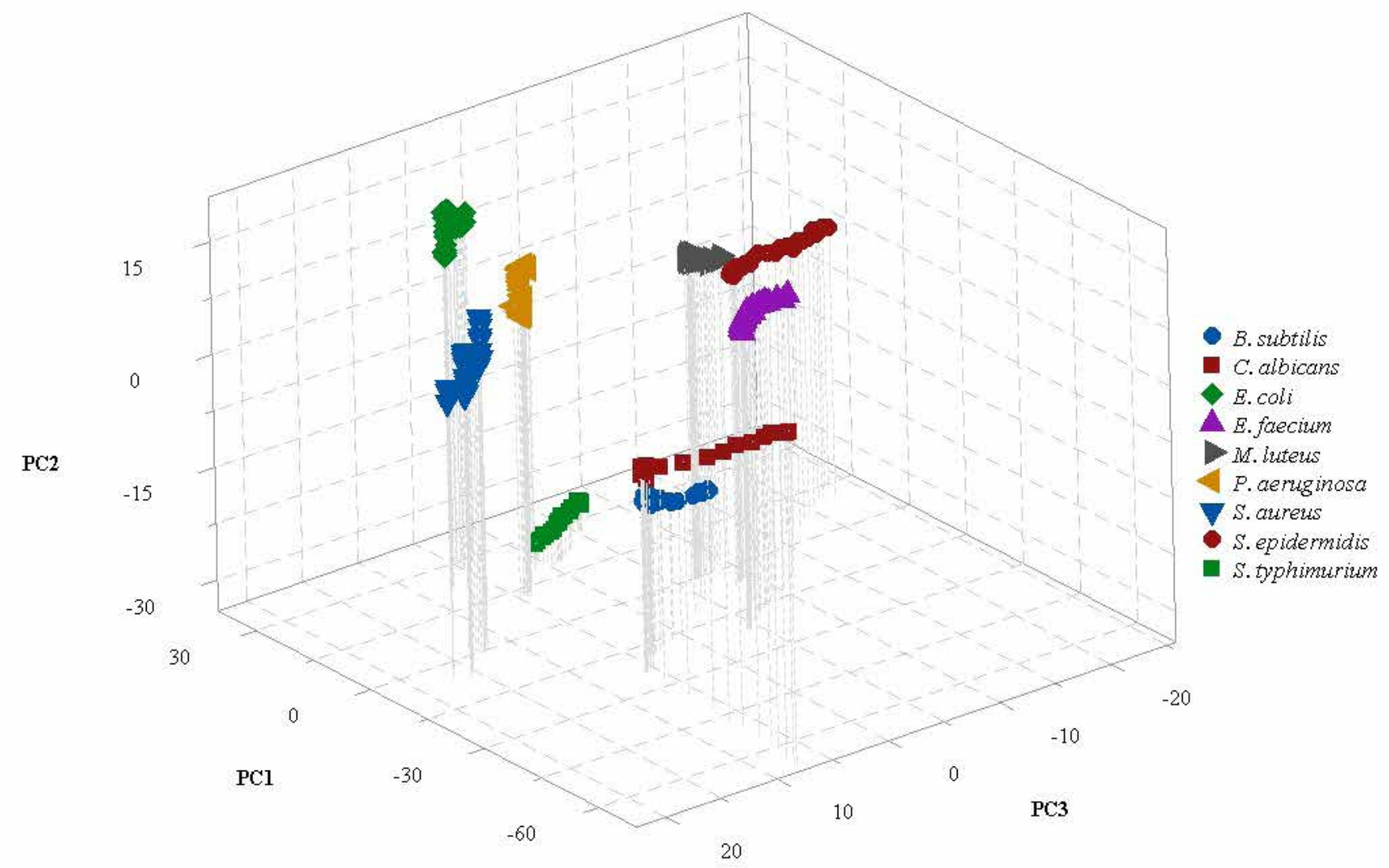

FIGURE 2 - PCA of Bacillus subtilis (ATCC 6633), Candida albicans (ATCC 10231), Enterococcus faecium (ATCC 8459), Escherichia coli (ATCC 8739), Micrococcus luteus (ATCC 10240), Pseudomonas aeruginosa (ATCC 9027), Salmonella typhimurium (ATCC 14028), Staphylococcus aureus (ATCC 6538), and Staphylococcus epidermidis (ATCC 12228) microbial growth. 
TABLE III - Confusion matrix for the LDA model obtained from FTIR-ATR spectra between 800 and $2000 \mathrm{~cm}^{-1}$ after first derivative and smoothing with 4 PC predictors

\section{Microorganisms}

Classification

obtained from

PCA/LDA model

\begin{tabular}{|c|c|c|c|c|c|}
\hline 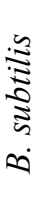 & 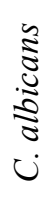 & 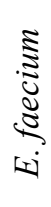 & $\underset{\tilde{U}}{\tilde{0}}$ & $\begin{array}{l}\frac{a}{3} \\
\frac{a}{3} \\
\dot{z}\end{array}$ & $\begin{array}{c}0 \\
5 \\
0 \\
.5 \\
0 \\
3 \\
0 \\
8 \\
0 \\
0\end{array}$ \\
\hline
\end{tabular}

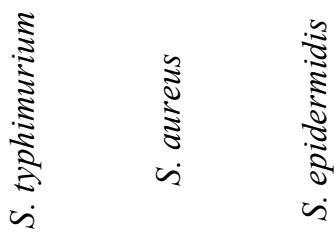

$\frac{\substack{0 \\ \frac{\pi}{0}}}{0}$

\begin{tabular}{|c|c|c|c|c|c|c|c|c|c|c|}
\hline \multirow{3}{*}{ B. subtilis } & $20^{\mathrm{a}}$ & $0^{\mathrm{a}}$ & $0^{\mathrm{a}}$ & $0^{\mathrm{a}}$ & $0^{\mathrm{a}}$ & $0^{\text {a }}$ & $0^{\mathrm{a}}$ & $0^{\mathrm{a}}$ & $0^{\mathrm{a}}$ & $100^{\mathrm{a}}$ \\
\hline & $20^{b}$ & $0^{\mathrm{b}}$ & $0^{\mathrm{b}}$ & $0^{\mathrm{b}}$ & $0^{\mathrm{b}}$ & $0^{\mathrm{b}}$ & $0^{\mathrm{b}}$ & $0^{\mathrm{b}}$ & $0^{\mathrm{b}}$ & $100^{\mathrm{b}}$ \\
\hline & $10^{\mathrm{c}}$ & $0^{\mathrm{c}}$ & $0^{\mathrm{c}}$ & $0^{\mathrm{c}}$ & $0^{\mathrm{c}}$ & $0^{\mathrm{c}}$ & $0^{\mathrm{c}}$ & $0^{\mathrm{c}}$ & $0^{\mathrm{c}}$ & $100^{c}$ \\
\hline \multirow{3}{*}{ C. albicans } & $0^{\text {a }}$ & $20^{\mathrm{a}}$ & $0^{\mathrm{a}}$ & $0^{\mathrm{a}}$ & $0^{\mathrm{a}}$ & $0^{\mathrm{a}}$ & $0^{\mathrm{a}}$ & $0^{\mathrm{a}}$ & $0^{\mathrm{a}}$ & $100^{\mathrm{a}}$ \\
\hline & $0^{\mathrm{b}}$ & $20^{b}$ & $0^{\mathrm{b}}$ & $0^{\mathrm{b}}$ & $0^{\mathrm{b}}$ & $0^{\mathrm{b}}$ & $0^{\mathrm{b}}$ & $0^{\mathrm{b}}$ & $0^{\mathrm{b}}$ & $100^{\mathrm{b}}$ \\
\hline & $0^{\mathrm{c}}$ & $10^{\mathrm{c}}$ & $0^{\mathrm{c}}$ & $0^{\mathrm{c}}$ & $0^{\mathrm{c}}$ & $0^{\mathrm{c}}$ & $0^{\mathrm{c}}$ & $0^{\mathrm{c}}$ & $0^{\mathrm{c}}$ & $100^{c}$ \\
\hline \multirow{3}{*}{ E. faecium } & $0^{\mathrm{a}}$ & $0^{\mathrm{a}}$ & $20^{\mathrm{a}}$ & $0^{\mathrm{a}}$ & $0^{\mathrm{a}}$ & $0^{\mathrm{a}}$ & $0^{\mathrm{a}}$ & $0^{\mathrm{a}}$ & $0^{\mathrm{a}}$ & $100^{\mathrm{a}}$ \\
\hline & $0^{\mathrm{b}}$ & $0^{\mathrm{b}}$ & $20^{b}$ & $0^{\mathrm{b}}$ & $0^{\mathrm{b}}$ & $0^{\mathrm{b}}$ & $0^{\mathrm{b}}$ & $0^{\mathrm{b}}$ & $0^{\mathrm{b}}$ & $100^{\mathrm{b}}$ \\
\hline & $0^{\mathrm{c}}$ & $0^{\mathrm{c}}$ & $9^{c}$ & $0^{\mathrm{c}}$ & $0^{\mathrm{c}}$ & $0^{\mathrm{c}}$ & $0^{\mathrm{c}}$ & $0^{\mathrm{c}}$ & $0^{\mathrm{c}}$ & $100^{\mathrm{c}}$ \\
\hline \multirow{3}{*}{ E. coli } & $0^{\mathrm{a}}$ & $0^{\mathrm{a}}$ & $0^{\mathrm{a}}$ & $20^{a}$ & $0^{\mathrm{a}}$ & $0^{\mathrm{a}}$ & $0^{\mathrm{a}}$ & $0^{\mathrm{a}}$ & $0^{\mathrm{a}}$ & $100^{\mathrm{a}}$ \\
\hline & $0^{b}$ & $0^{\mathrm{b}}$ & $0^{\mathrm{b}}$ & $20^{\mathrm{b}}$ & $0^{\mathrm{b}}$ & $0^{\mathrm{b}}$ & $0^{\mathrm{b}}$ & $0^{\mathrm{b}}$ & $0^{\mathrm{b}}$ & $100^{\mathrm{b}}$ \\
\hline & $0^{\mathrm{c}}$ & $0^{\mathrm{c}}$ & $0^{\mathrm{c}}$ & $15^{\mathrm{c}}$ & $0^{\mathrm{c}}$ & $0^{\mathrm{c}}$ & $0^{\mathrm{c}}$ & $0^{\mathrm{c}}$ & $0^{\mathrm{c}}$ & $100^{c}$ \\
\hline \multirow{3}{*}{ M. luteus } & $0^{\mathrm{a}}$ & $0^{\mathrm{a}}$ & $0^{\mathrm{a}}$ & $0^{\mathrm{a}}$ & $20^{\mathrm{a}}$ & $0^{\mathrm{a}}$ & $0^{\mathrm{a}}$ & $0^{\mathrm{a}}$ & $0^{\mathrm{a}}$ & $100^{\mathrm{a}}$ \\
\hline & $0^{\mathrm{b}}$ & $0^{\mathrm{b}}$ & $0^{b}$ & $0^{\mathrm{b}}$ & $20^{b}$ & $0^{\mathrm{b}}$ & $0^{\mathrm{b}}$ & $0^{\mathrm{b}}$ & $0^{\mathrm{b}}$ & $100^{\mathrm{b}}$ \\
\hline & $0^{\mathrm{c}}$ & $0^{\mathrm{c}}$ & $0^{\mathrm{c}}$ & $0^{\mathrm{c}}$ & $11^{\mathrm{c}}$ & $0^{\mathrm{c}}$ & $0^{\mathrm{c}}$ & $0^{\mathrm{c}}$ & $0^{\mathrm{c}}$ & $100^{\mathrm{c}}$ \\
\hline \multirow{3}{*}{ P. aeruginosa } & $0^{\mathrm{a}}$ & $0^{\mathrm{a}}$ & $0^{\mathrm{a}}$ & $0^{\mathrm{a}}$ & $0^{\mathrm{a}}$ & $20^{\mathrm{a}}$ & $0^{\mathrm{a}}$ & $0^{\mathrm{a}}$ & $0^{\mathrm{a}}$ & $100^{\mathrm{a}}$ \\
\hline & $0^{\mathrm{b}}$ & $0^{\mathrm{b}}$ & $0^{\mathrm{b}}$ & $0^{\mathrm{b}}$ & $0^{\mathrm{b}}$ & $20^{b}$ & $0^{\mathrm{b}}$ & $0^{\mathrm{b}}$ & $0^{\mathrm{b}}$ & $100^{\mathrm{b}}$ \\
\hline & $0^{\mathrm{c}}$ & $0^{\mathrm{c}}$ & $0^{\mathrm{c}}$ & $0^{\mathrm{c}}$ & $0^{\mathrm{c}}$ & $13^{\mathrm{c}}$ & $0^{\mathrm{c}}$ & $0^{\mathrm{c}}$ & $0^{\mathrm{c}}$ & $100^{\mathrm{c}}$ \\
\hline \multirow{3}{*}{ S. typhimurium } & $0^{\mathrm{a}}$ & $0^{\mathrm{a}}$ & $0^{\mathrm{a}}$ & $0^{\mathrm{a}}$ & $0^{\mathrm{a}}$ & $0^{\mathrm{a}}$ & $20^{\mathrm{a}}$ & $0^{\mathrm{a}}$ & $0^{\mathrm{a}}$ & $100^{\mathrm{a}}$ \\
\hline & $0^{\mathrm{b}}$ & $0^{\mathrm{b}}$ & $0^{\mathrm{b}}$ & $0^{\mathrm{b}}$ & $0^{\mathrm{b}}$ & $0^{\mathrm{b}}$ & $20^{b}$ & $0^{\mathrm{b}}$ & $0^{\mathrm{b}}$ & $100^{\mathrm{b}}$ \\
\hline & $0^{\mathrm{c}}$ & $0^{\mathrm{c}}$ & $0^{\mathrm{c}}$ & $0^{\mathrm{c}}$ & $0^{\mathrm{c}}$ & $0^{\mathrm{c}}$ & $5^{c}$ & $0^{\mathrm{c}}$ & $0^{\mathrm{c}}$ & $100^{c}$ \\
\hline \multirow{3}{*}{ S. aureus } & $0^{\mathrm{a}}$ & $0^{\mathrm{a}}$ & $0^{\mathrm{a}}$ & $0^{\mathrm{a}}$ & $0^{\mathrm{a}}$ & $0^{\mathrm{a}}$ & $0^{\mathrm{a}}$ & $20^{\mathrm{a}}$ & $0^{\mathrm{a}}$ & $100^{\mathrm{a}}$ \\
\hline & $0^{\mathrm{b}}$ & $0^{\mathrm{b}}$ & $0^{\mathrm{b}}$ & $0^{\mathrm{b}}$ & $0^{\mathrm{b}}$ & $0^{\mathrm{b}}$ & $0^{\mathrm{b}}$ & $20^{b}$ & $0^{\mathrm{b}}$ & $100^{\mathrm{b}}$ \\
\hline & $0^{\mathrm{c}}$ & $0^{\mathrm{c}}$ & $0^{\mathrm{c}}$ & $0^{\mathrm{c}}$ & $0^{\mathrm{c}}$ & $0^{\mathrm{c}}$ & $0^{\mathrm{c}}$ & $14^{\mathrm{c}}$ & $0^{\mathrm{c}}$ & $100^{c}$ \\
\hline \multirow{3}{*}{ S. epidermidis } & $0^{\mathrm{a}}$ & $0^{\mathrm{a}}$ & $0^{\mathrm{a}}$ & $0^{\mathrm{a}}$ & $0^{\mathrm{a}}$ & $0^{\mathrm{a}}$ & $0^{\mathrm{a}}$ & $0^{\mathrm{a}}$ & $20^{\mathrm{a}}$ & $100^{\mathrm{a}}$ \\
\hline & $0^{\mathrm{b}}$ & $0^{\mathrm{b}}$ & $0^{\mathrm{b}}$ & $0^{b}$ & $0^{\mathrm{b}}$ & $0^{\mathrm{b}}$ & $0^{b}$ & $0^{\mathrm{b}}$ & $20^{b}$ & $100^{\mathrm{b}}$ \\
\hline & $0^{\mathrm{c}}$ & $0^{\mathrm{c}}$ & $5^{c}$ & $0^{\mathrm{c}}$ & $2^{c}$ & $0^{\mathrm{c}}$ & $0^{c}$ & $0^{\mathrm{c}}$ & $14^{\mathrm{c}}$ & $67^{\mathrm{c}}$ \\
\hline \multirow{3}{*}{ Total } & $100 \%{ }^{\mathrm{a}}$ & $100 \%{ }^{\mathrm{a}}$ & $100 \%^{\mathrm{a}}$ & $100 \%{ }^{\mathrm{a}}$ & $100 \%{ }^{\mathrm{a}}$ & $100 \%{ }^{\mathrm{a}}$ & $100 \%{ }^{\mathrm{a}}$ & $100 \%^{\mathrm{a}}$ & $100 \%{ }^{\mathrm{a}}$ & $100 \% \%^{\mathrm{a}}$ \\
\hline & $100 \%{ }^{\mathrm{b}}$ & $100 \%{ }^{\mathrm{b}}$ & $100 \%{ }^{\mathrm{b}}$ & $100 \%{ }^{\mathrm{b}}$ & $100 \%{ }^{\mathrm{b}}$ & $100 \%{ }^{b}$ & $100 \%{ }^{\mathrm{b}}$ & $100 \%{ }^{\mathrm{b}}$ & $100 \%{ }^{\mathrm{b}}$ & $100 \%{ }^{\mathrm{b}}$ \\
\hline & $100 \% \%^{\mathrm{c}}$ & $100 \% \mathrm{o}^{\mathrm{c}}$ & $64 \%{ }^{c}$ & $100 \%{ }^{\mathrm{c}}$ & $85 \%{ }^{\mathrm{c}}$ & $100 \% \mathrm{c}^{\mathrm{c}}$ & $100 \% \mathrm{o}^{\mathrm{c}}$ & $100 \%{ }^{c}$ & $100 \%{ }^{\mathrm{c}}$ & $94 \%{ }^{\mathrm{c}}$ \\
\hline
\end{tabular}

${ }^{a}$ Classification model

${ }^{\mathrm{b}}$ Cross-validation (Internal)

${ }^{\mathrm{c}}$ External validation 
TABLE IV - Contingency table for presence/absence of microbial growth and FTIR/ATR method for rapid identification of microbial contaminants in pharmaceutical products

\section{FTIR/ATR method identification}

Microbial growth

$\begin{array}{llll}\text { Absence } & \text { Total } & \text { Results }\end{array}$

\begin{tabular}{lcccc}
\hline Negative & 135 & 27 & 162 & Specificity $=135 / 162=83.3 \%$ \\
\hline Positive & 7 & 101 & 108 & Sensitivity $=101 / 108=93.5 \%$ \\
\hline
\end{tabular}

\section{CONCLUSION}

A Fourier transform infrared with attenuated total reflectance spectrometry (FTIR-ATR) method for the rapid identification of contaminants in pharmaceutical products was developed and validated by assessing the sensitivity, specificity and limit of detection. Principal components analysis (PCA) and linear discriminant analysis (LDA) were used to obtain a predictive model capable of distinguishing Bacillus subtilis (ATCC 6633), Candida albicans (ATCC 10231), Enterococcus faecium (ATCC 8459), Escherichia coli (ATCC 8739), Micrococcus luteus (ATCC 10240), Pseudomonas aeruginosa (ATCC 9027), Salmonella typhimurium (ATCC 14028), Staphylococcus aureus (ATCC 6538), and Staphylococcus epidermidis (ATCC 12228) microbial growth. Microbial identification using PCA/ LDA based on the developed FTIR-ATR method was compatible with those obtained using traditional microbiological methods outlined in the USP and Brazilian Pharmacopoeia. Therefore, we conclude that FTIR-ATR spectroscopy may be used to provide rapid identification of microbial contaminants in pharmaceutical products.

\section{ACKNOWLEDGMENTS}

The authors wish to thank the Fundação de Amparo à Pesquisa do Estado de São Paulo (FAPESP) for fellowships and financial support. Jim Hesson proofread the manuscript (https://www.academicenglishsolutions.com).

\section{REFERENCES}

Agência Nacional de Vigilância Sanitária (ANVISA). 5.5.3.1 Ensaios microbiológicos para produtos não estéreis. Brasília: Farmacopeia Brasileira, 2010.

Bugno A, Lira RS, Oliveira WA, Almodovar AAB, Saes DPS, Pinto TJA. Application of the BacT/ALERT ${ }^{\circledR} 3 \mathrm{D}$ system for sterility testing of injectable products. Braz J Microbiol. 2015;46(3):743-7.

Bugno A, Saes DPS, Almodovar AAB, Dua K, Awasthi R, Ghisleni DDM, Hirota MT, Oliveira WA, Pinto TJA. Performance survey and comparison between rapid sterility testing method and pharmacopeia sterility test. J Pharm Innov. 2018;13(1):27-35.

David R, Maurer LJ. Fourier transform infrared (FT-IR) spectroscopy: a rapid tool for detection and analysis of foodborne pathogenic bacteria. In: Méndez-Vilas, editors. Current research, technology and education topics in applied microbiology and microbial biotechnology. Badajoz: Formatex, 2010. pp. 1582-94.

Denyer SP, Baird RM. Guide to microbiological control in pharmaceuticals and medical devices. 2nd ed. New York: Taylor \& Francis Group, 2007.

Ester MC. Rapid microbiological methods in the pharmaceutical industry. Washington: Interpharm/CRC, 2003.

Ferreira MRS, Lourenço FR, Ohara MT, Bou-Chacra NA, Pinto TJA. Na innovative challenge test for solid cosmetics using freeze-dried microorganisms and electrical methods. J Microbiol Methods. 2014;104:104-9. 
Filip Z, Herrmann S, Kubat J. FT-IR spectroscopic characteristics of differently cultivated Bacillus substilis. Microbiol Res. 2014:159(3):257-62.

Fischer G, Braun S, Thissen R, Dott W. FT-IR spectroscopy as a tool for rapid identification and intra-species characterization of airborne filamentous fungi. J Microbiol Methods. 2006;64(1):63-77.

Helm D, Naumann D. Identification of some bacterial cell components by FT-IR spectroscopy. FEMS Microbiol Lett. 1995;126(1):75-9.

Hongyu, K., Sandanielo, V. L. M., Junior, G. J. O. Análise de Componentes Principais: resumo teórico, aplicação e interpretação. Eng Sci. 2015; 1(5): 1-8.

Kane SR, Létant SE, Murphy GA, Alfaro TM, Krauter PW, Mahnke R, Legler TC, Raber E. Rapid, high-throughput, culture-based PCR methods to analyze samples for viable spores of Bacillus anthracis and its surrogates. J Microbiol Methods. 2009;76(3):278-84.

Kuligowski J, Quintás G, Herwig C, Lendl B. A rapid method for the differentiation of yeast cells grown under carbon and nitrogen-limited conditions by means of partial least squares discriminant analysis employing infrared micro-spectroscopic data of entire yeast cells. Talanta. 2012;99:566-73.

Liu X, Guan Y, Cheng S, Huang Y, Yan Q, Zhang J, Huang G, Zheng J, Liu T. Development of a highly sensitive lateral immunochromatographic assay for rapid detection of Vibrio parahaemolyticus. J Microbiol Methods. 2016;131:78-84.

Lourenço FR, Francisco FL, Ferreira MRS, Pinto TJA, Löbenberg R, Bou-Chacra NA. Design space approach for preservative system optimization of an anti-aging eye fluid emulsion. J Pharm Pharm Sci. 2015;18(2):551-61.

Lourenço FR, Kaneko TM, Pinto TJA. Estimativa da incerteza em ensaio de detecção de endotoxina bacteriana pelo método de gelificação. Braz. J. Pharm. Sci. 2005;41(4):437-443.

Maurischat S, Szabo I, Baumann B, Malorny B. Rapid realtime PCR methods to distinguish Salmonella Enteritidis wildtype field isolates from vaccine strains Salmovac SE/ Gallivac SE and AviPro SAMONELLA VAC E. J. Microbial Methods. 2015;112:92-8.

Pacheco FL, Pinto TJA, The bacterial diversity of pharmaceutical clean rooms analyzed by the fatty acid methyl ester technique. PDA J Pharm Sci Technol. 2010;64(2):156-66.

Paiva, A. P. D. Metodologia Superficie de Respostas e Análise de Componentes Principais em Otimização de Processo de Manufatura com Múltiplas Respostas Correlaciondas. Itajubá, 2006.
Parveen S Kaur S, Wilson SA, Kenney JL, McCornick WM, Gupta RK. Evaluation of growth based rapid microbiological methods for sterility testing of vaccines and other biological products. Vaccine. 2011;29:8012-23.

Pinto TJA, Kaneko TM, Pinto AF. Métodos alternativos para enumeração e identificação de microrganismos. In: Pinto TJA, Kaneko TM, Pinto AF, editors. Controle biológico de qualidade de produtos farmacêuticos, correlatos e cosméticos. 4th ed. Barueri: Manole, 2015. pp. 129-51.

Shah N, Naseby DC. Validation of constitutively expressed bioluminescent Pseudomonas aeruginosa as a rapid microbiological quantification tool. Biosens Bioelectron. 2015;68:447-53.

Song C, Li J, Liu J, Liu Q. Simple sensitive rapid detection of Escherichia coli O154:H7 in food samples by label-free immunofluorescence strip sensor. Talanta. 2016;156-157:42-7.

Taguri T, Oda Y, Sugiyama K, Nishikawa T, Endo T, Izumiyama S, Yamazaki M, Kura F. A rapid detection method using flow cytometry to monitor the risk of Legionella in bath water. J Microbiol Methods. 2011;86(1):25-32.

Tidwell JE, Dawson-Andoh B, Adedipe EO, Nkansah K, Dietz MJ. Can near-infrared spectroscopy detect and differentiate implant-associated biofilms? Clin Orthop Relat Res. 2015;473(11):3638-46.

Tong MY, Jiang C, Armstrong DW. Fast detection of Candida albicans and/or bacteria in blood plasma by "sample-selffocusing" using capillary electrophoresis-laser-induced fluorescence. J Phar Biomed Anal. 2010;53(1):75-80.

Trullols E, Ruisánchez I, Rius FX. Validation of qualitative analytical methods. Trends in Anal. Chem. 2004;53(2):137-145.

Ugarova NN, Lomakina GY, Modestova Y, Chernikov SV, Vinokurova NV, Otrashevskaya EV, Gorbachev VY. A simplified ATP method for the rapid control of cell viability in a freeze-dried BCG vaccine. J Microbiol Methods. 2016;130:48-53.

United States Pharmacopeia. $<61>$ Microbiological examination of nonsterile products: microbial enumeration tests. Rockville: United States Pharmacopeial Convention, 2016a.

United States Pharmacopeia. <62> Microbiological examination of nonsterile products: tests for specified microorganisms. Rockville: United States Pharmacopeial Convention, $2016 \mathrm{~b}$.

United States Pharmacopeia. $<1223>$ Validation of alternative microbiological methods. Rockville: United States Pharmacopeial Convention, 2016c. 
Rapid identification of microbial contaminants in pharmaceutical products using a PCA/LDA-based FTIR-ATR method

Varella, C. A. A. Análise Multivariada Aplicada às Ciencias Agrárias. Rio de Janeiro, 2010.

Verdonk GP, Willemse MJ, Hoefs SG, Van Den Heuvel ER. The most probable limit of detection (MPL) for rapid microbiological methods. J Microbiol Methods. 2010;82(3):193-7.
Wu SM, Chen J, Ai XX, Yan ZY. Detection of Escherichia coli in drugs with antibody conjugated quantum dots as immunofluorescence probes. J Phar Biomed Anal. 2013;7879:9-13.

Received for publication on $15^{\text {th }}$ October 2018 Accepted for publication on $16^{\text {th }}$ May 2019 